\title{
Radiological diagnosis of rectocutaneous fistulas in a cat - a case report
}

\author{
Anna Łojszczyk-Szczepaniak, Renata Komsta, Piotr Dębiak, Lisiak Barbara \\ University of Life Sciences, Faculty of Veterinary Medicine, Department and Clinic of Animal Surgery, \\ Laboratory of Radiology and Ultrasonography, Lublin, Poland
}

Received August 19, 2013

Accepted April 24, 2014

\begin{abstract}
Abscess and perirectal fistulas are common in humans but not so in animals. Fistulas located in tissues surrounding the anus are usually described in the course of furunculosis in dogs. This study presents the case of a one-year-old cat in which two rectocutaneous fistulas had formed. This process was a result of the chronic inflammation of tissues around the base of the tail due to the drainage of an abscess. The animal was referred for radiological examination with clinical signs of dyschezia. Faecal material was discharged only through the fistulas situated on both sides of the tail. The aim of the radiological examination was to preoperatively determine the course of the fistula tract and to identify their internal openings. Fistulography revealed that both fistulas were connected with each other and with the rectal lumen. Their external opening was located at the height of the $4^{\text {th }}$ caudal vertebra, $1.5 \mathrm{~cm}$ (fistula on the right) and $2 \mathrm{~cm}$ (fistula on the left) from the wall of the rectum. The fistula located on the right side branched cranially. The rectal lumen in this area was significantly narrowed. Abscess formation resulting in the development of rectocutaneous fistulas has not yet been described in dogs or cats. In the present case, fistulography made it possible to identify directly the source and course of the fistula canal. This examination should be complemented by other diagnostic modalities, such as a contrast examination of the gastrointerstinal tract, ultrasound evaluation, and magnetic resonance imaging.
\end{abstract}

Perianal abscess, perianal glands, rectum occlusion, fistula, fistulography

Abscesses and perirectal fistulas are a common proctological disease in humans (Rickard 2005; Jander et al. 2006). They develop mainly as a result of the infection and inflammation of perirectal tissues, including the impaction and infection of the perianal glands (Hermann's glands) located at the dentate line of the rectum, at the base of the anal crypts (Rickard 2005; Jander et al. 2006; Whiteford 2007; Abdul and Mosa Al-Rekabi 2009; Arendt et al. 2011). In animals, similar cases are rarely observed. In dogs and cats, numerous anal glands, significant in the etiopathogenesis of abscesses and fistulas in humans, are located in the intermediate zone of the mucous membrane of the rectum. They do not have much clinical significance in contrast to the perianal sinuses (sinus paranales), situated on both sides of the anus, between the external and internal anal sphincter (Duijkeren 1995; König and Liebich 2007). The wall of the sinus contains a number of large apocrine tubular glands (gll. sinus paranalis), the role of which is to secrete odoriferous substances of still unknown significance. The openings of the excretory ducts are located in the cutaneous zone of rectum mucous, and they are the most common site for the development of an inflammatory state and the formation of abscesses (Chomiak et al. 1996; Duijkeren 1995; König and Liebich 2007).

Among the possible causes of perianal inflammation in animals are superinfection by faecal material, infection and impaction of the perianal glands or anal crypts with microabscesses formation, inflammation of the apocrine glands, and infection of hair follicles (Duijkieren 1995; Arons on 2003). Fistulas located in tissues surrounding the anus and connected with the anal canal are described in the course of furunculosis in dogs, 
whose aethiology is related to multifactoral immune-mediated disorders (Jamieson et al. 2002).

This study presents a radiological assessment of perianal fistulas that developed secondarily to the drainage of an abscess in the base of the tail in a cat. Similar cases have not been described in dogs or cats.

\section{Materials and Methods}

\section{Clinical symptoms}

A male cat, about 1 year old, was referred for radiological examination to the Laboratory of Radiology and Ultrasonography. The cat had an abscess located near the base of the tale, on its ventral side, approximately $1 \mathrm{~cm}$ from the anus. According to the owner, 2 weeks before the visit to the clinic, the abscess ruptured. A week later, the owner observed that faecal masses were eliminated only through two fistulas, which developed at the site of the ruptured abscess, on both sides of the base of the tale. The cat had not been previously treated. The aim of diagnostic imaging procedures was to determine preoperatively the precise course of the fistula tracts and to identify their internal openings.

\section{Radiological examination}

The radiographic study of the abdomen was performed in the right lateral and ventrodorsal recumbency (Plate VI, Figs 1, 2). Radiographs did not show any abnormalities in the size, shape, position, or radiopacity of visceral organs located in the peritoneal cavity. There was also no increase in opacity and no presence of gas in the soft tissues around the rectum and anus, which could indicate the presence of a radiopaque foreign body, infection by anaerobic bacteria, or perforation of the large intestine.

Subsequently, the animal was prepared for fistulography. It was premedicated with xylazine $(2 \mathrm{mg} / \mathrm{kg} \mathrm{BW})$ (Biowet, Pulawy, Poland) and atropine $(0.1 \mathrm{mg} / \mathrm{kg} \mathrm{BW})$ (WZF, Polfa SA, Warsaw, Poland). The fistula canals were cannulated and flushed with sterile saline introduced into the fistulas. Then a catheter was introduced into the fistula on the right side of the anus. By means of the catheter attached to a syringe, a positive iodinated non-ionic contrast agent was administered (Visipaque, iodixanolum $320 \mathrm{mg} \mathrm{I} / \mathrm{ml}$, GE Healthcare, Oslo), and radiography was conducted in ventrodorsal recumbency. In order to visualize better the course of the fistula, another portion of the contrast agent was administered, and radiographs were performed again in the right lateral as well as in the ventrodorsal position. Next, the contrast agent was administered to the fistula located on the left side, and radiographs were performed again in two perpendicular projections.

\section{Results}

The examination revealed that both fistulas were connected with each other and with the rectal lumen (Plate VII, Fig. 3). The external opening of both fistulas was situated at the height of the $4^{\text {th }}$ caudal vertebra, $1.5 \mathrm{~cm}$ (fistula on the right) and $2 \mathrm{~cm}$ (fistula on the left) from the rectum wall. The diameter of the fistulas was up to $2 \mathrm{~mm}$. The fistula situated on the right side, about $7 \mathrm{~mm}$ from the external opening, branched cranially. Both crura were about $5 \mathrm{~mm}$ long, and one of them was connected to the rectal lumen. There were no branches in the left fistula. The rectal lumen narrowed towards the anus, and the contrast agent did not reach its final segment.

In order to determine the length of rectum stenosis, the catheter was introduced into the anus, which was possible only up to a length of $7 \mathrm{~mm}$. The radiograph performed in lateral recumbency showed that the anal canal, filled with faecal masses and the contrast agent, was visible about $8 \mathrm{~mm}$ before the catheter (Plate VII, Fig. 4).

After the examination, the patient was sent back to the primary private clinic, where he underwent surgery.

\section{Discussion}

Chronic fistulas occur in animals mostly as a result of the migration of a foreign body (usually grass awns and other fragments of plants) through soft tissues (Aronson 2003; Brennan et al. 2004; Hunt et al. 2004). There are also descriptions of internal posttraumatic fistulas and fistulas acquired as a complication of ovariohysterectomia (Arons on 
2003; Holt et al. 2006; Packer et al. 2004). A case of bronchocutaneous fistula caused by the formation of an abscess in the subcutaneous tissue of the neck has also been reported (Yamagishi et al. 2000).

Abscess formation resulting in the development of rectocutaneous fistulas has not been described in dogs or cats. In humans, such changes are usually due to the infection of the perianal glands. They are located in the perianal, intersphincteric, ischiorectal, and supralevator planes (Rickard 2005; Kolodziejczak and Kowalski 2006; Jander et al. 2006; Whiteford 2007; Abdul and Mosa Al-Rekabi 2009; Arendt et al. 2011). When the process enters the chronic phase, fistulas are often formed in the adjacent soft tissues. They connect the gastrointestinal tract with the surrounding visceral organs and peritoneal cavity (internal fistulas) or skin surface (external fistulas) (Rickard 2005).

Clinical signs depend on the location of the pathologic process and the extent of changes. In the case of perianal abscesses located superficially, only local symptoms are observed, such as irritation, pain, and the swelling of skin around the anus. If fistulas are formed as a result of an inflammatory process, one may simultaneously observe purulent perianal discharge as well as dyschezia, alternating constipation and diarrhea, rectal tenesmus, haematochezia, or even discharge of faecal material through the fistulas (Rickard 2005; Whiteford 2007; Arendt et al. 2011).

In humans, the "higher" the abscess is located, the more dominant are the general symptoms (Kolodziejczak and Kowalski 2006). The most intense, throbbing rectal and pelvic pain is reported in supralevator and intersphincteral abscesses. Intersphincteral as well as ischiorectal abscesses which occur most frequently in humans, may also be associated with fever (Rickard 2005; Abdul and A1-Rekabi 2009). In the case of "high" supralevator abscesses, there are also symptoms such as urinary incontinence and systemic toxicity (Kolodziejczak and Kowalski 2006).

The diagnosis of perirectal fistulas is based on physical examination and diagnostic imaging techniques. A detailed evaluation includes location of the external and internal openings, the course of the primary tract in relation to the anal sphincter complex, the presence of secondary extensions and other diseases that may be a complication of the process, especially in the case of high fistulas (Pickhardt et al. 2002; Rickard 2005; Arendt et al. 2011). The most widely used classification is the one suggested by Parks, who takes into account the direction and relation of the fistula tract to the internal and external sphincters as well as the levator ani muscle. On the basis of these features, Parks classifies anal fistulas into intersphincteric, transsphincteric, suprasphincteric, and extrasphincteric groups (Kolodziejczak and Kowalski 2006; Whiteford 2007; Arendt et al. 2011). Another classification by Godsall and Miles, is also useful in determining the course of the fistula tract. According to their rule, fistulas with an external opening above a horizontal line drawn through the centre of the anal canal usually drain directly into the anal canal, whereas fistulas lying below this line usually drain to the midline (Rickard 2005).

The choice of imaging techniques depends on the type of tissues affected by the inflammatory process. One of the available diagnostic methods is fistulography, which makes it possible to determine directly the source and course of the fistula canal. It is particularly useful in cases of external fistulas, and when non-radiopaque foreign bodies are suspected (Matteucci et al. 1999; Pickhardt 2002; Kolodziejczak and Kowalski 2006; Felix and Ifeanyi 2011). The examination begins with a survey radiograph, which shows anatomical relationships between the organs of the abdominal cavity (Felix and Ifeanyi 2011). In the case of fistulas it is possible to observe radiographically the loss of the organ edge and serosal margin details caused by the inflammatory reaction and adhesions, tissue swelling, chronic periosteal reaction in the adjacent skeletal system, and the presence of subcutaneous gas or foreign bodies in the soft tissues (Matteucci et al. 
1999; Yamagishi et al. 2000; Aronson 2003). Fistulography is effective in identifying the internal opening of the fistula in $17-25 \%$ of cases and in determining its course in $90 \%$ of cases. In $48 \%$ of cases it is also possible to evaluate additional pathological states caused by previous surgical treatment (Arendt et al. 2011).

In fistulography there is also a risk of complication. Because the examination is painful, premedication of the animal is necessary. The examination also involves the risk of perforating the fistula and causing inflammation to spread to the surrounding tissues. Allergic reactions to the contrast agent, ranging from mild skin lesions to severe reactions, such as vomiting, difficulty in breathing, and weakness, have been rarely reported (Felix and Ifeanyi 2011). None of these side effects were observed in the examined patient.

The best results in the diagnosis of pathological processes in the perianal area can be obtained by the combination of fistulography with the contrast examination of the gastrointestinal tract or only the colon, ultrasound examination, and magnetic resonance imaging (Pickhardt 2002; Rickard 2005; Kolodziejczak and Kowalski 2006; Turek and Verhoeven 2008). Contrast examination of the gastrointestinal tract is particularly important in cases in which obstruction of the intestinal lumen is suspected (Zatloukal et al. 2004). An important examination is also the transrectal ultrasound which increases the effectiveness of detecting the internal opening to $53 \%$ by determining the location and course of the fistula tract in relation to the anal sphincter complex (Arendt et al. 2011). Moreover, in the cases of fistula formation, it also reveals the infection of the surrounding soft tissues. Therefore, the diagnosis of all changes around the anus should include the exclusion of rectal inflammation (Yamagishi et al. 2000; Aronson 2003; Felix and Ifeanyi 2011).

A very precise method of fistula imaging is the magnetic resonance technique. It is used especially in cases of numerous, complex, and recurrent changes (Pickhardt et al. 2002). That is because contrast examination may be insufficient to visualize the entire fistula tract, especially in acute cases in which inflammatory granulomatosis obliterates the lumen of the duct (Rickard 2005). The examination may be supplemented by computed tomography, useful in evaluating diseases that are often associated with fistulas, such as abscesses or neoplastic tumours (Pickhardt et al. 2002). Additionally, precise surgical evaluation under anaesthesia is essential for the assessment of the fistula tract (Felix and Ifeanyi 2011).

In the present case, the location of the abscess and rectocutaneous fistula did not correspond to the position of the perianal glands. In this area there are many hair follicles, inflammation of which may result in the formation of abscesses (Aronson 2003). The location and course of the fistula tract, confirmed by radiological examination, was consistent with Goodsall's rule. The high position of the abscess with respect to the anus caused drainage directly into the rectal canal. The fistula canal was located in the anatomical position of the coccygeus and sacrocaudalis (coccygeus) ventralis lateralis muscles, the levator muscle of the anus, and the rectococcygeus muscle which forms a muscular, longitudinal layer along the wall of the rectum (Chomiak et al. 1996; König and Liebich 2007). Since neither of the fistulas maintained connection with the external and internal anal sphincters, they were classified on the basis of their location into the group of extrasphincteric fistulas.

In this study, contrast examination made it possible to visualize accurately the internal and external openings as well as the course of the fistula tract. The contrast enhancement of the rectum lumen proved effective in determining the location of rectal occlusion. Unfortunately, transrectal ultrasonography was impossible because of the low body weight of the animal. Since radiological examination is insufficient in evaluating soft tissue pathology, it is necessary to complement it with other imaging techniques. 


\section{References}

Abdul I, Mosa Al-Rekabi A 2009: Risk of fistula development following drainage of ano-rectal abscess bacteriological study. Kufa Med Journal 12: 6-11

Arendt J, Trompeta J, Podwiński A, Rdes J 2011: Perirectal fistula - diagnostic and therapeutic problems (In Polish). Chir Polska 4: 73-80

Aronson L 2003: Rectum and anus. In: Slatter DH (Ed.): Textbook of Small Animal Surgery. Saunders, Philadelphia, pp. 682-707

Brennan SF, Connery N, Tobin E, Mooney CT, Jones BR 2004: Gastrocutaneus fistula as a result of migration of a foreign body in a dog. JSAP 45: 304-306

Chomiak M, Flieger S, Lewandowski M 1996: Intestine. In: Splanchology of Domestic Animals (In Polish). AR, Lublin, pp. 104-131

Duijkeren E 1995: Disease conditions of canine anal sacs. JSAP 36: 12-16

Felix EO, Ifeanyi AJ 2011: Rare cases of rectocutaneous fistulas basis radiological techniques and presentations. J Med Med Sci 2: 885-888

Holt PE, Bohannon J, Day MJ 2006: Vaginoperitoneal fistula after ovariohysterectomy in three bitches. JSAP 47: 744-746

Hunt GB, Worth A, Marchevsky A 2004: Migration of wooden skewer foreign bodies from the gastrointestinal tract in eight dogs. JSAP 45: 362-367

Jamieson PM, Simpson JW, Kirby BM, Else RW 2002: Association between anal furunculosis and colitis in the dog: preliminary observations. JSAP 43: 109-114

Jander K, Kołodziejczyk A, Miglus S, Kuszlak T, Luksa-Pydych J, Jędrychowski J, Gorniok-Niechcial A 2006 : Perianal abscess in the course of a cervical cancer (In Polish). Wiadomości Lekarskie 59: 122-124

Kolodziejczak M, Kowalski B 2006: Perianal absceses and fistulas in the anus - current diagnostic and therapeutic approach (In Polish). Postepy Nauk Medycznych 5: 183-187

König HE, Liebich HG 2007: Veterinary Anatomy of Domestic Mammals. Schattauer, Stuttgart, 356 p.

Matteucci ML, Spaulding K, Dassler C, Lee D 1999: Ultrasound diagnosis: intra-abdominal wood foreign body. Vet Rad Ultrasound 40: 513-516

Packer RA, Frank PM, Chambers JN 2004: Traumatic subarachnoid-pleural fistula in a dog. Vet Rad Ultrasound 45: $523-527$

Pickhardt PJ, Bhalla S, Balfe DM 2002: Acquired gastrointestinal fistulas: classification, etiologies, and imaging evaluation. Radiology 10: 9-23

Rickard MJF 2005: Anal abscesses and fistulas. ANZ J Surg 75: 64-72

Turek B, Verhoeven G 2008: Atresia coli in foal - case report. Med Weter 64: 280-282

Whiteford MH 2007: Perianal abscess/fistula disease. Clin Colon Rectal Surg 20: 102-109

Yamagishi N, Yamada K, Ishikawa H, Yamada H 2000: Bronchocutaneus fistula in a dog. Vet Rad Ultrasound 41: $422-424$

Zatloukal J, Crha M, Lorenzová J, Husník R, Kohout P, Nečas A 2004: The comparative advantage of plain radiography in diagnosis of obstruction of the small intestine in dogs. Acta Vet Brno 73: 365-374 
Plate VI

Łojszczyk-Szczepaniak A. et al.: Radiological... pp. 255-259

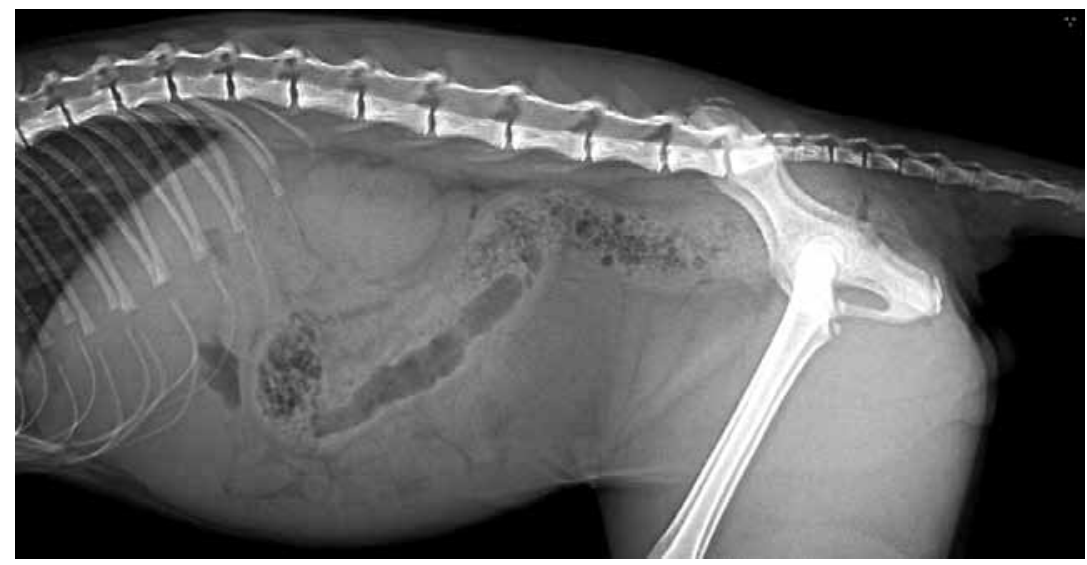

Fig. 1. A survey radiograph of the abdominal cavity of the cat in lateral recumbency

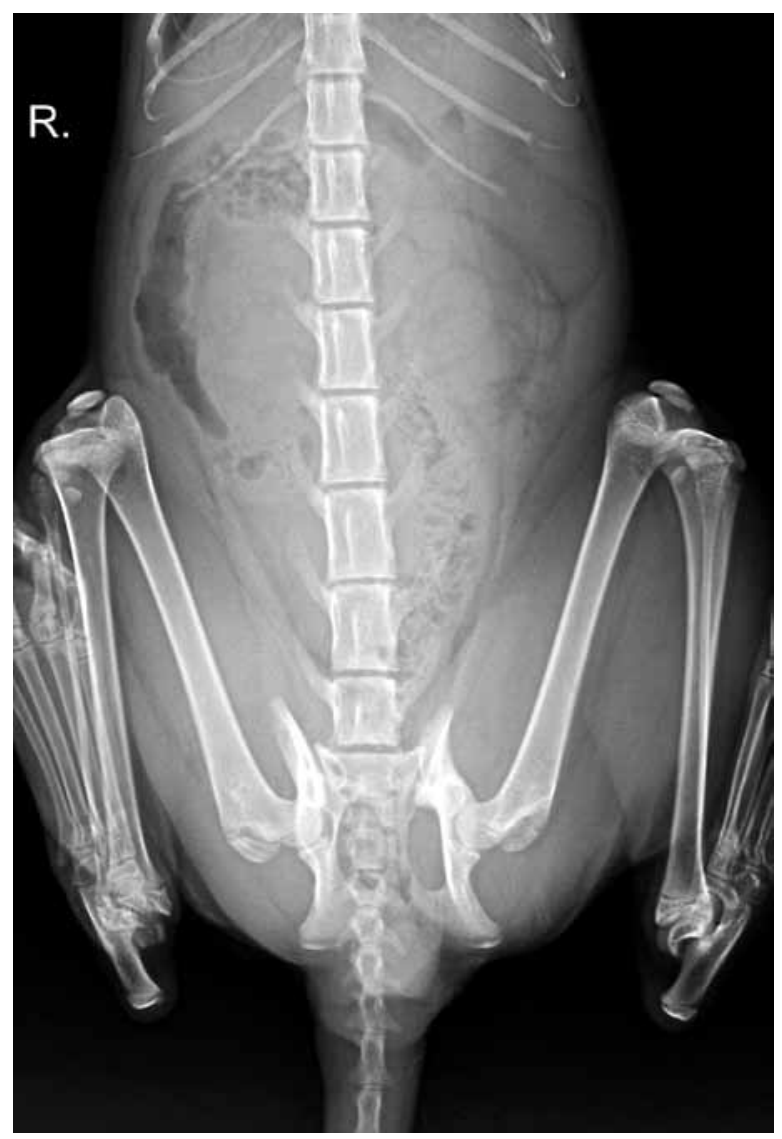

Fig. 2. A survey radiograph of the abdominal cavity of the cat in vetrodorsal recumbency 


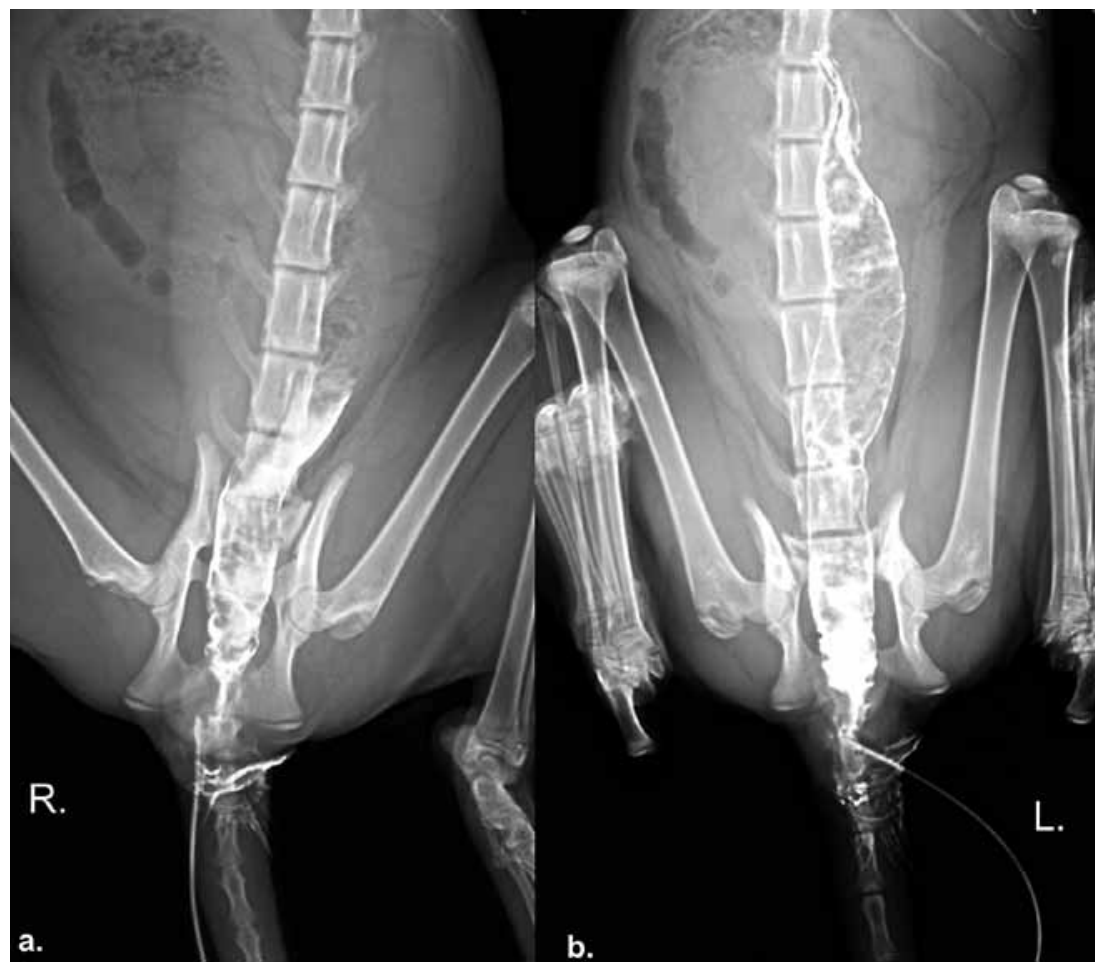

Fig. 3. Fistulography. A visible fistula on the right side, connected with the rectal lumen (a) and the fistula on the left side. A catheter reaches into the rectal lumen (b)

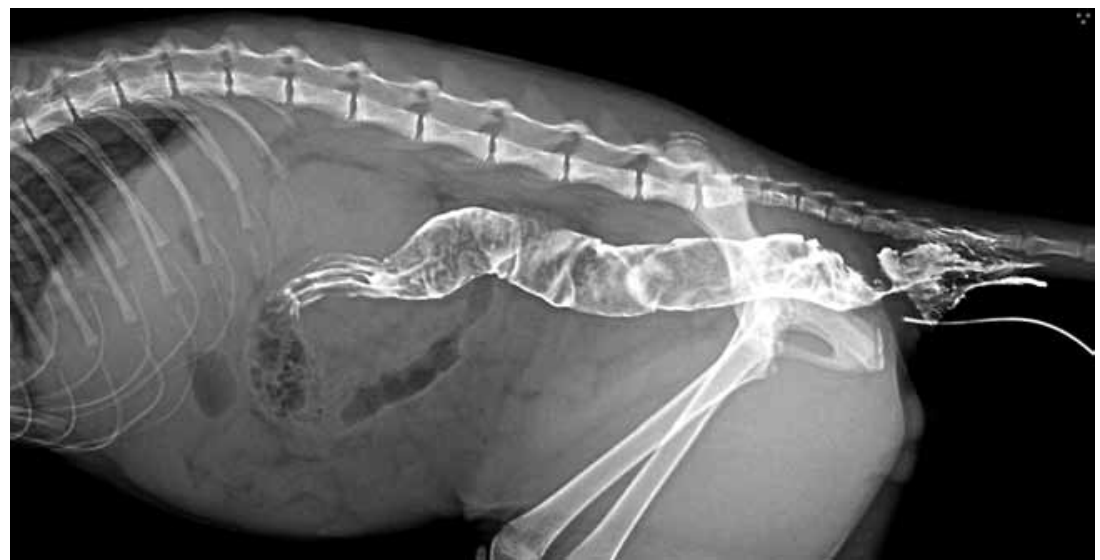

Fig. 4. A radiograph in lateral recumbency after fistulography. A visible narrowing of the rectal lumen 